\title{
Effect of Reconstituted Pulmonary Surfactant Containing the 6000-Dalton Hydrophobic Protein on Lung Compliance of Prematurely Delivered Rabbit Fetuses
}

\author{
SHOU-HAW YU, DUNCAN WALLACE, BHAGU BHAVNANI, GORAN ENHORNING, \\ PAUL G. R. HARDING, AND FRED POSSMAYER \\ Departments of Obstetrics and Gynaecology [S-H.Y., P.G.R.H., F.P.] and Biochemistry [F.P.], The University of \\ Western Ontario, London, Ontario, Canada N6A 5A5; Department of Obstetrics and Gynaecology [D.W., B.B.], \\ McMaster University, Hamilton, Ontario, Canada L8N 3Z5, and Department of Obstetrics and \\ Gynaecology [G.E.], SUNY at Buffalo, New York 14222
}

\begin{abstract}
Chloroform:methanol extracts of bovine pulmonary surfactant contain small hydrophobic proteins, designated surfactant-associated apoproteins 6,000 (SAP6), but do not contain the major surfactant-associated 35,000-dalton glycoprotein, designated SAP-35. Examination of lipid extract surfactant on sodium dodecylsulfatepolyacrylamide gel electrophoresis revealed hydrophobic proteins with apparent molecular masses of $15,000,7,000$, and 3,500 daltons prior to reduction. After reduction, the 15,000-dalton species largely disappeared and was replaced by a 5,000-dalton species. In addition, the 7000and 3500-daIton species exhibited a slightly enhanced mobility. Amino acid analysis demonstrated that SAP-6 possesses a more highly hydrophobic profile than SAP-35. Combining the protein-containing fractions from silicic acid chromatography of lipid extract with synthetic dipalmitoylphosphatidylcholine produced a reconstituted surfactant preparation which was just as active as lipid extract surfactant on a pulsating bubble surfactometer. The reconstituted surfactant contained SAP-6 but not SAP-35. Pressure-volume studies revealed that, at the optimal dose, reconstituted surfactant containing half the SAP-6 concentration of lipid extract exhibited similar effectiveness to lipid extract surfactant in promoting lung expansion with prematurely delivered rabbit fetuses of 27 days gestation. Reconstituted surfactant with an identical SAP-6 protein concentration as lipid extract possessed the same biological properties as the preparation with $1 \%$ SAP-6 protein. These studies support the view that an artificial surfactant composed of synthetic or semisynthetic lipids plus human SAP-6 produced via biotechnology could be useful for prevention and/or treatment of the neonatal respiratory distress syndrome. (Pediatr Res 23: 23-30, 1988)
\end{abstract}

\section{Abbreviations}

DPPC, dipalmitoylphosphatidylcholine

DPPG, dipalmitoylphosphatidylglycerol

PAGE, polyacrylamide gel electrophoresis

PE, phosphatidylethanolamine

PG, phosphatidylglycerol

SAP, surfactant-associated protein

Received June 10, 1987; accepted August 26, 1987.

Correspondence and reprint requests Fred Possmayer, University Hospital, London, Ontario, Canada N6A 5A5.

Supported by grants from the Medical Research Council of Canada and from the Ontario Thoracic Society.

\author{
SDS, sodium dodecylsulfate \\ $\mathbf{R}_{\max }$, maximum radius \\ $\mathbf{R}_{\min }$, minimum radius
}

Pulmonary surfactant is synthesized in the type II cells of the alveolus, assembled into lamellar bodies, and secreted into the alveolar space by exocytosis (1-4). To reduce the surface tension and stabilize the alveoli, the lipid components of pulmonary surfactant must adsorb and spread at the air-liquid interface as a monolayer with their polar headgroups in the aqueous phase and their fatty acid moieties extending into the air (3-5). During expansion and contraction, the surface film becomes enriched with DPPC (3-7). This phospholipid lowers the surface tension to the low value required to prevent alveolar collapse during expiration (3-7). Phospholipids that are not present in the surface monolayer have a negligible effect on surface and tension. The realization that DPPC, with or without other lipids, does not readily adsorb and spread at the air-liquid interface focused attention on the role of surfactant-associated proteins. Initial studies involved the major surfactant protein, which has been detected in all species examined as minor species with nominal molecular masses of approximately 28,000 daltons and as one or more major glycosylated and sialated species of approximately 35,000 daltons $(2,8)$. Evidence, primarily obtained with the Wilhelmy plate surface balance, indicates that this 35,000 dalton SAP facilitates the adsorption and spreading of DPPC (9-11). However, it has become apparent that lipid extracts of pulmonary surfactant, which are largely depleted of protein, exhibit the essential characteristics of natural surfactant (4-6) with the pulsating bubble surfactometer (12) and were also effective in promoting lung expansion and survival with prematurely delivered fetal rabbits and lambs (13-17). The biological effectiveness of such protein-poor surfactant preparations has been confirmed through clinical trials involving both the alleviation of the effects of the respiratory distress syndrome and by the prevention of respiratory distress through prophylactic treatment at birth (1822).

It has recently become apparent that lipid extract surfactant is devoid of SAP-35 but contains a number of small hydrophobic proteins collectively known as SAP-6 (23-29). Previous studies by this laboratory have revealed that the hydrophobic apoproteins can be separated from the PC fraction by column chromatography on silicic acid (23). Combining the protein fraction, which also contains PG and PE, with the PC fraction (23) or 
with synthetic DPPC (30) resulted in active reconstitutes as evaluated by the pulsating bubble surfactometer. The present studies were undertaken to further clarify the relationship between the role of SAP-35 and SAP- 6 in surfactant activity and to determine whether reconstituted surfactant containing only SAP-6 possesses biological as well as biophysical activity.

\section{METHODS}

Surfactant preparation. Natural bovine surfactant was prepared by a modification of methods previously published by this laboratory $(31,32)$. Lipid extract surfactant was produced by extraction with chloroform:methanol (33). The surfactant was further purified by precipitation of phospholipid fraction with $20 \mathrm{vol}$ of cold acetone (32). Lipid extract surfactant was normally stored in chloroform:methanol $(9: 1)$ at $-20^{\circ} \mathrm{C}$. The concentration of lipid extract was determined by measuring the phospholipid phosphorous content and multiplying this value by 25 (34).

Lipid extract surfactant was prepared for biophysical and biological assays as follows: the chloroform extracts were evaporated to dryness on the sides of glass tubes with a stream of $\mathrm{N}_{2}$. Saline containing $1.0 \mathrm{mM} \mathrm{CaCl}{ }_{2}$ was added and the samples were dispersed, first by gentle vortexing to avoid foaming, and then by brief sonication with a bath type sonicator (Bransonic 12). The temperature of the sonicator bath was approximately $40^{\circ} \mathrm{C}$ during this process. The samples used for the lung compliance studies were dispersed at a concentration of $25 \mathrm{mg} / \mathrm{ml}$. After diluting to $10 \mathrm{mg} / \mathrm{ml}$ with saline- $1 \mathrm{mM} \mathrm{CaCl}_{2}$, the biophysical activity of these preparations was assessed on the pulsating bubble surfactometer, as indicated below. For some experiments in which only biophysical parameters were evaluated, the lipid extract surfactant was directly dispersed at $10 \mathrm{mg} / \mathrm{ml}$. Samples were stored at $-20^{\circ} \mathrm{C}$. Although this has not been studied in detail, in our experience samples prepared as indicated above do not lose appreciable biophysical activity during storage for over 1 yr at $-20^{\circ} \mathrm{C}$. Normally, the samples were thawed only once prior to testing for biological activity and diluted with saline-1 $\mathrm{mM} \mathrm{CaCl}_{2}$ as required.

Preparation of reconstituted surfactant. Lipid extract surfactant was fractionated by chromatography on silicic acid columns using chloroform:methanol as previously described $(23,35)$. This procedure produces a minor lipid peak containing PG, PE plus the hydrophobic proteins, and a major lipid peak containing PC. The minor lipid peak, which corresponds to fraction I plus fraction II in our former studies, was taken to dryness and redispersed in chloroform:methanol (9:1). For reconstitution, the protein-containing samples were mixed with an appropriate amount of DPPC in chloroform:methanol $(9: 1)$ and taken to dryness under $\mathrm{N}_{2}$. Saline- $1 \mathrm{mM} \mathrm{CaCl}$ solution and fine glass beads were added and the suspension was shaken at room temperature for $1 \mathrm{~h}$. (The term "reconstitution" is used to mean addition of SAP-6 protein back to lipid; it does not imply that the DPPC was obtained from surfactant). Reconstituted surfactant was prepared to yield a relative concentration of either 1 or $2 \%$ protein as a percentage of phospholipid. The approximate relative concentrations of the lipids in the reconstituted surfactant preparations were, for $1 \%$ protein: DPPC, $90 \%$; PG, $7.5 \%$; PE, $2.5 \%$; and for $2 \%$ protein: DPPC, $80 \%$; PG, $15 \%$; PE, $5.0 \%$.

Protein analysis. The protein composition of bovine pulmonary surfactant was examined by SDS-PAGE using a modification (30) of the method of Laemmli (36). The high proportion of lipid (approximately 98\%) necessitated the following modifications. The $15 \%$ polyacrylamide separation gels were cast with $6 \mathrm{M}$ urea. The concentration of SDS in the running buffer was increased to $0.18 \%$. The sample buffer contained 5\% SDS, 0.05 $\mathrm{M}$ Tris- $\mathrm{HCl}, \mathrm{pH} 8.5$, and where indicated, 2-mercaptoethanol. The $20-\mathrm{cm}$ gels were subjected to electrophoresis at $100 \mathrm{~V}$ for 18 $\mathrm{h}$ followed by several hours at $200 \mathrm{~V}$ until the dye front had emerged from the gel for at least $1 \mathrm{~h}$. The gels were stained with Coomassie-blue as previously described (23) followed by silver stain from NEN (DuPont Co., Wilmington, DE) as indicated by the manufacturer. Amino acid analyses were conducted using a Beckman model $119 \mathrm{CL}$ single column amino acid analyser. The protein samples were hydrolyzed in $6 \mathrm{~N} \mathrm{HCl}$ for $24 \mathrm{~h}$ at $115^{\circ} \mathrm{C}$ in evacuated sealed tubes.

Biophysical assay. The biophysical activity of natural surfactant, lipid extract surfactant and reconstituted surfactant was determined using the pulsating bubble surfactometer introduced by Enhorning (12). With this apparatus, a bubble communicating with ambient air is created in a suspension of the surfactant preparation. The bubble is pulsated between a $R_{\max }$ of $0.55 \mathrm{~mm}$ and a $R_{\min }$ of $0.4 \mathrm{~mm}$. The pressure difference across the bubble surface is monitored with a pressure transducer. Surface tension is calculated by the law of Laplace which states that the pressure difference across a sphere is directly proportional to twice the surface tension and indirectly proportional to the radius. The surface tension at $\mathrm{R}_{\max }$ and $\mathrm{R}_{\min }$ are expressed. Samples are normally tested at a concentration of $10 \mathrm{mg}$ lipid $/ \mathrm{ml}(1.0 \%, \mathrm{w} /$ v). Lipid extract surfactant contains $2 \%$ protein by weight corresponding to a final protein concentration of $0.02 \%(\mathrm{w} / \mathrm{v})$ in the test samples.

Biological assay. Biological activity was assayed by conducting pressure-volume loops with fetal rabbits delivered at 27 days gestation (term 31 days) as described previously $(13,14)$. Briefly, the does were given a lethal dose of sodium pentobarbitol and the uterus excised. The fetuses were killed in utero, delivered, and weighed. After tracheotomy, polyethylene tubes were inserted and the fetuses were placed in a water bath of $37^{\circ} \mathrm{C}$. Either saline or surfactant sample was inserted. The tracheal catheters from the fetuses being tested were connected to glass tubes containing $2 \mathrm{ml}$ of air which in turn were connected to a central reservoir of colored water. Pressure volume loops were produced by raising the reservoir so that its surface attained set levels above the fetuses. Pressure was maintained for $15 \mathrm{~s}$ at each of two breathing cycles. Changes in the displacement of air into and out of the lung were determined photographically. Values were corrected for body weight.

The lipid extract and reconstituted surfactant samples used in these studies were at a concentration of $25 \mathrm{mg} / \mathrm{ml}(\mathrm{w} / \mathrm{v})$ based on lipid. In order to facilitate volume measurements and to maintain the volumes of fluid within reasonable limits, sufficient saline- $1 \mathrm{mM} \mathrm{CaCl} \mathrm{Ca}_{2}$ was added to adjust the volume of the lower doses to $50 \mu \mathrm{l}$. Saline controls received $50 \mu \mathrm{l}$ of saline- $1 \mathrm{mM}$ $\mathrm{CaCl}_{2}$

Twenty-five fetuses from four does were used to determine the pressure-volume loops with different amounts of lipid extract surfactant as follows: $0.25 \mathrm{mg}$, three fetuses; $0.5 \mathrm{mg}$, three fetuses; $1.0 \mathrm{mg}$, five fetuses; $1.25 \mathrm{mg}$, five fetuses; $1.5 \mathrm{mg}$, four fetuses; $1.875 \mathrm{mg}$, five fetuses. Eleven fetuses from two different does were used in the studies with different amounts of reconstituted surfactant containing $1 \%$ protein relative to lipid: $0.25 \mathrm{mg}$, two fetuses; $0.5 \mathrm{mg}$, one fetus; $0.75 \mathrm{mg}$, three fetuses; $1.0 \mathrm{mg}$, two fetuses; $1.25 \mathrm{mg}$, three fetuses. In addition, five fetuses were treated with $50 \mu \mathrm{l}$ of saline- $1 \mathrm{mM} \mathrm{CaCl}_{2}$ and 10 fetuses were studied as untreated controls. The studies comparing the effectiveness of reconstituted surfactant containing $2 \%$ protein relative to phospholipid were conducted using litter mates for the two different doses of phospholipid. At the 1.25-mg dose, four fetuses were used for lipid extract surfactant and seven for the reconstituted preparation containing $2 \%$ protein. For the $1.5-\mathrm{mg}$ dose, six fetuses were treated with lipid extract surfactant and the same number with reconstituted surfactant.

Other methods. Total protein could be approximated by the method of Lowry et al. (37) using SDS to disperse the lipid. As has been alluded to previously (31), different responses were obtained for surfactant protein and bovine serum albumin compared to amino acid analyses. In addition, during the course of this study it became apparent that different color yields were obtained by Lowry for the hydrophobic proteins separated by column chromatography. As a consequence, protein concentra- 
tion was calculated from the amino acid analyses measured as indicated above. Statistical significance was determined using Student's $t$ test for independent variables.

Materials. Standard chemical reagents were obtained from Fisher Scientific Co., Pittsburgh, PA; DPPC was obtained from Sigma Chemical Company, St. Louis, MO; pregnant rabbits of known gestation were purchased from Don Rieman's Fur Ranch, Petersburg, Ontario, Canada.

\section{RESULTS}

The protein composition of natural bovine surfactant and its lipid extract was examined by SDS-PAGE using the modified method described in the text. Electrophoresis of natural surfactant in the absence of 2-mercaptoethanol revealed a high molecular weight complex at the top of the separation gel, and a sharp band with an apparent molecular mass of 70,000 daltons. These bands showed positive staining with both Coomassie-blue and silver (Lane 2, Fig. $1 A$ and $B$ ). In addition, broad diffuse bands, which did not photograph well with Coomassie-blue but displayed clear reactivity with silver stain, could be observed with apparent molecular masses of approximately 15,000, 7,000, and 3,500 daltons. Phospholipid could be observed as a grey smudge below the 3500-dalton band. Electrophoresis of natural surfactant in the presence of sulfhydryl reagent, revealed a strong prominent band with an apparent molecular mass of 35,000 daltons and a sharp band with an apparent molecular mass of 28,000 daltons which were stained with both Coomassie-blue and silver stain (lane 2, Fig. $1 A$ and $B$ ). In addition, a faint silver-positive band corresponding to 7000 daltons and darkly stained bands of 5000 and 3500 daltons were observed with the reduced sample of natural surfactant. Electrophoresis of the hydrophobic protein fraction from silicic acid revealed the same pattern as for lipid extract in Figure 1 but the 7,000 dalton and 3,500 dalton may be slightly reduced relative to the 15,000 dalton species (not shown).

Electrophoresis of lipid extract surfactant failed to reveal any indication of the large molecular weight apoproteins at the top of the gel or the $70,000,35,000$, or 28,000 dalton surfactant apoproteins either in the presence or absence of mercaptoethanol (lanes 4 and 5, Fig. $1 A$ and $B$ ). The low molecular weight proteins were more evident than with whole surfactant. In the absence of mercaptoethanol prominent silver-staining bands were observed with apparent molecular masses of $15,000,7,000$, and 3,500 daltons (lane 4, Fig. $1 B$ ). After reduction, the 15,000dalton band almost completely disappeared and was replaced by a band at 5,000 daltons (lane 5, Fig. $1 B$ ). The 7000- and 3500dalton bands stained somewhat more strongly and migrated slightly farther in the presence of sulfhydryl reagent. Although it is difficult to observe a clear separation between the 5000- and 3500-dalton bands in the photograph (Fig. 1), distinct separate bands could be observed with this and with other gels, especially during development. Since the samples electrophoresed in Figure 1 represent complete samples of natural and lipid extract surfactant, the complete protein profile should be represented.

In keeping with the chloroform solubility of the small apoproteins present in lipid extract surfactant, amino acid analysis of these preparations revealed a highly hydrophobic amino acid pattern containing large quantities of leucine and valine and relatively small amounts of highly charged amino acids (Table 1). In contrast, the $35-\mathrm{K}$ apoprotein contained a high proportion of glycine and glutamic acid. The amino acid composition of SAP-6 contained $69 \%$ nonpolar and $80 \%$ uncharged amino acids compared to the $52 \%$ nonpolar and $68 \%$ uncharged amino acids present in SAP-35. These calculations have considered the proportions of glutamine present in amino acid sequence data from

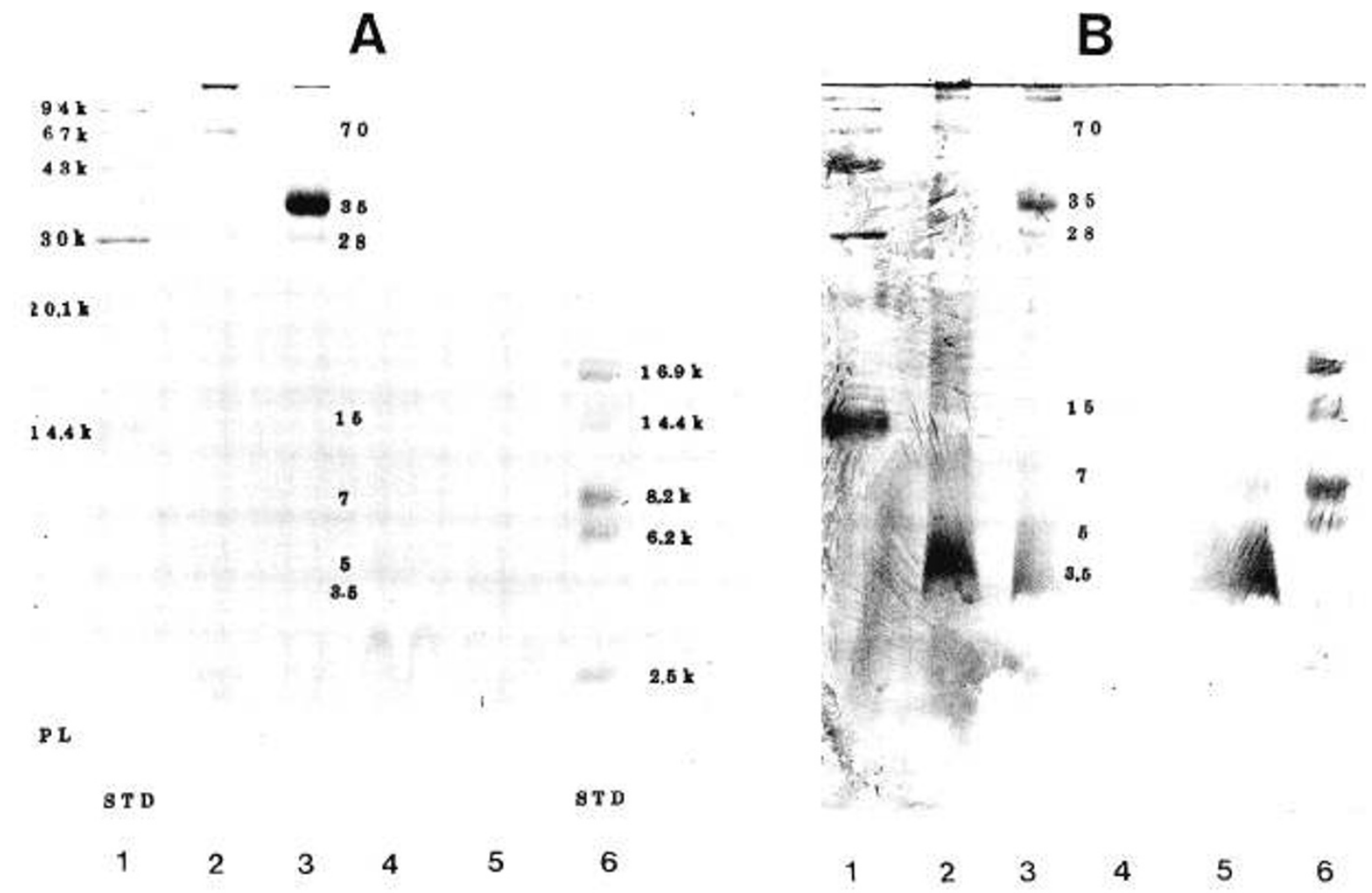

Fig. 1. SDS-PAGE of bovine pulmonary surfactant and lipid extract surfactant. The gel was subjected to electrophoresis as described in the text. The gel was stained with Coomassie blue $(A)$ and subsequently with silver stain $(B)$. Lane 1 , high molecular weight standards; lane 2, bovine pulmonary surfactant, $25 \mu \mathrm{g}$ protein; lane 3 , bovine pulmonary surfactant with mercaptoethanol, $25 \mu \mathrm{g}$ protein; lane 4, lipid extract surfactant, $4 \mu \mathrm{g}$ protein; lane 5, lipid extract surfactant, with mercaptoethanol, $4 \mu \mathrm{g}$ protein; lane 6 , low molecular weight standards. 
Table 1. Amino acid composition of SAP-6 and SAP-35* from bovine pulmonary surfactant

\begin{tabular}{ccc}
\hline & \multicolumn{2}{c}{ \% Composition } \\
\cline { 2 - 3 } Amino acid & SAP-6 & SAP-35 \\
\hline Asp & 6.7 & 10.7 \\
Thr & 3.3 & 3.3 \\
Ser & 3.0 & 2.3 \\
Glx & 7.8 & 14.3 \\
Pro & 6.0 & 5.0 \\
Gly & 9.0 & 18.3 \\
Ala & 5.4 & 5.7 \\
Cys & 3.6 & 2.6 \\
Val & 13.2 & 6.5 \\
Met & 2.4 & 2.2 \\
Ile & 7.8 & 3.8 \\
Leu & 19.3 & 8.5 \\
Tyr & 1.1 & 3.0 \\
Phe & 1.4 & 2.4 \\
His & 0.8 & 1.8 \\
Lys & 3.2 & 4.5 \\
Arg & 5.9 & 5.5 \\
\hline
\end{tabular}

* SAP- 6 was isolated as indicated in the text. SAP-35 was prepared by high-performance liquid chromatography. A sample of natural surfactant was dispersed in $8 \mathrm{M}$ urea- $0.05 \%$ trifluoroacetic acid, $\mathrm{pH} 2.5$, applied to a C18 reverse phase column and the SAP-35 eluted with a gradient containing $0.05 \%$ trifluoroacetic acid and 2-propanol.

bovine SAP-6 and the cDNA sequences of canine SAP-35 (38) and SAP-6 (39).

Biophysical activity was assessed with the pulsating bubble surfactometer (12). No difference could be observed between the ability of natural pulmonary surfactant or its lipid extract to reduce the surface tension of a pulsating bubble to approximately $27 \mathrm{mN} \cdot \mathrm{m}^{-1}$ at maximum bubble size $(0.55 \mathrm{~mm})$ and near 0 $\mathrm{mN} \cdot \mathrm{m}^{-1}$ at minimum bubble size $(0.4 \mathrm{~mm})$ (Table 2$)$. Reconstituted surfactant was prepared by mixing the apoprotein fraction from silicic acid column chromatography mentioned above with appropriate amounts of DPPC. Because initial recombinations were based on protein values determined using the Lowry procedure, the protein concentration, as a proportion of lipid, was adjusted to $1 \%(\mathrm{w} / \mathrm{w})$ which is half the protein concentration of lipid extract surfactant as determined by amino acid analysis (see "Methods"). Nevertheless, samples prepared with either $1 \%$ protein or $2 \%$ protein relative to lipid displayed similar biophysical characteristics to natural surfactant or lipid extract surfactant (Table 2). In contrast, lipid mixtures without protein cannot lower the surface tension of the pulsating bubble to these low values $(23,30)$.

Previous investigations have demonstrated that lipid extract surfactant is just as effective as natural surfactant in facilitating lung expansion and in promoting survival with prematurely delivered rabbit fetuses of 27 days gestation $(13,14)$. These former studies revealed an optimal dose for lung expansion of $1.25 \mathrm{mg}$ phospholipid and no effect of volume over a considerable range. In keeping with these earlier findings, increasing the amount of lipid extract surfactant or reconstituted surfactant from 0.25 to $1.25 \mathrm{mg}$ resulted in a progressive increase in lung compliance (Fig. 2A). Increasing the amount of lipid extract phospholipid to 1.5 and $1.875 \mathrm{mg}$ resulted in a small decrease in lung volume, particularly during the second loop but this was not significantly different from the values obtained with $1.25 \mathrm{mg}$ phospholipid.

In order to economize on material and because the biophysical activity of reconstituted surfactant with $1 \%$ protein was similar to that with $2 \%$ protein, the dose-response curve study was conducted using the lower amount of protein (Fig. $2 B$ ). In contrast to lipid extract surfactant, there was little effect at 0.25 and $0.5 \mathrm{mg}$ phospholipid and maximal lung volume was observed
Table 2. Comparison of biophysical activity of Natural surfactant, lipid extract surfactant, and reconstituted surfactant on pulsating bubble surfactometer

\begin{tabular}{lrr} 
& \multicolumn{2}{c}{$\begin{array}{c}\text { Surface tension }(\mathrm{mN} / \\
\mathrm{m})^{*}\end{array}$} \\
\cline { 2 - 3 } \multicolumn{1}{c}{ Sample } & \multicolumn{2}{c}{$(n=3)$} \\
\cline { 2 - 3 } \multicolumn{1}{c}{$\mathrm{R}_{\max }$} & \multicolumn{1}{c}{$\mathrm{R}_{\min }$} \\
\hline Natural surfactant & $25.0 \pm 0.4$ & $0 \pm 0.0$ \\
Lipid extract surfactant & $27.0 \pm 1.2$ & $0 \pm 0.0$ \\
Reconstituted surfactant (1\% protein) & $28.0 \pm 2.0$ & $1.5 \pm 1.2$ \\
Reconstituted surfactant (2\% protein) & $28.0 \pm 2.5$ & $1.8 \pm 1.0$ \\
\hline
\end{tabular}

* Surfactant activity was assessed by monitoring the pressure difference across the pulsating bubble and determining the surface tension at a maximum bubble radius of $0.55 \mathrm{~mm}\left(\mathrm{R}_{\max }\right)$ and at minimum bubble radius of $0.4 \mathrm{~mm}\left(R_{\min }\right)$ after $1 \mathrm{~min}$ pulsation at $37^{\circ} \mathrm{C}$, using the Laplace equation which states that the pressure difference across a sphere is equal to twice the surface tension divided by the radius. Samples of lipid extract surfactant and reconstituted surfactant were incubated at $37^{\circ} \mathrm{C}$ for $1-2$ $\mathrm{h}$ before being tested. All samples were tested at a concentration of 10 $\mathrm{mg}$ lipid per $\mathrm{ml}$ in saline- $1 \mathrm{mM} \mathrm{CaCl}$.

with $1.0 \mathrm{mg}$ phospholipid. The pressure-volume loops observed with $1.0 \mathrm{mg}$ of reconstituted surfactant (1\% protein) were virtually indistinguishable from the pressure volume loops obtained with $1.25 \mathrm{mg}$, the optimal amount, of lipid extract surfactant.

Statistical evaluation of the pressure-volume curves obtained with either lipid extract or reconstituted surfactant ( $1 \%$ protein) versus saline- $1 \mathrm{~mm} \mathrm{CaCl}_{2}$ and air controls revealed a highly significant increase for all measurements with $1.0 \mathrm{mg}$ or more phospholipid which were beyond the $20-\mathrm{cm}$ pressure point of the first ascending loop. Comparison of the pressure-volume loops obtained with 1.0,1.25, and $1.5 \mathrm{mg}$ of lipid extract surfactant with those with $1.0 \mathrm{mg}$ reconstituted surfactant $(1.0 \%$ protein) revealed no significant differences in either loop. However, comparison of the pressure-volume loops obtained with $1.25 \mathrm{mg}$ lipid extract and $1.25 \mathrm{mg}$ reconstituted surfactant ( $1 \%$ protein) revealed that lipid extract was more effective $(0.25>p>0.025)$ for the 30-, 35-, and 30-cm $\mathrm{H}_{2} \mathrm{O}$ pressure measurements during the initial pressure-volume loops and for the $20-\mathrm{cm}$ values during the descending cycle of the second pressure-volume loop.

In separate experiments, the effectiveness of 1.25 and $1.5 \mathrm{mg}$ of reconstituted surfactant containing $2 \%$ protein relative to lipid were compared with the effectiveness of similar amounts of lipid extract surfactant. In order to maximize the possibility of distinguishing between these preparations, litter mates were used for the experiments with each concentration of surfactant. However, the pressure-volume loops obtained with 1.25 and $1.5 \mathrm{mg}$ reconstituted surfactant $(2 \%$ protein) were statistically indistinguishable from each other and from the pressure loops obtained with either concentration of lipid extract surfactant. In addition, no significant differences were observed between the results obtained with reconstituted surfactant containing $2 \%$ protein and the corresponding curves with $1 \%$ protein depicted in Figure $2 B$. Consequently, these pressure-volume curves are not shown. Rather, the data from these experiments are summarized with those from the experiments in Figure 2 by illustrating the relationship between the maximal lung volumes obtained during the first and second loops and the amounts of reconstituted and lipid extract applied (Fig. $3 A$ and $B$ ). Increasing amounts of lipid extract surfactant resulted in a steady increase in maximal lung volume up to $1.25 \mathrm{mg}$ phospholipid where the effect plateaued. In contrast, no increase in maximal lung volume was observed until $0.75 \mathrm{mg}$ of reconstituted surfactant ( $1 \%$ protein) was applied. Maximal lung volumes were observed with $1.0 \mathrm{mg}$ reconstituted surfactant, followed by a definite although statistically insignificant decline. The values obtained with reconstituted surfactant containing $2 \%$ protein, depicted with closed symbols, 
were virtually identical to those obtained with reconstituted surfactant containing $1 \%$ protein. It should be noted that neither the pressure volume loops obtained with 0.25 and $0.5 \mathrm{mg}$ of lipid extract surfactant or those obtained with equivalent amounts of reconstituted surfactant were significantly different from the controls. Taken together, the results obtained in these experiments indicate that reconstituted surfactant containing half the SAP-6 apoprotein content of lipid extract surfactant possessed similar biological activity to lipid extract but may not be as effective at low concentrations.

\section{DISCUSSION}

The presence of a large molecular weight protein designated glycoprotein A has been documented in pulmonary surfactant from a number of mammalian species $(2,8,11)$. When bovine surfactant was subjected to SDS-PAGE in the absence of mer- captoethanol, a large proportion of this protein remained at the top of the gel and the remainder appeared as a relatively sharp band at 70,000 daltons (Fig. 1, lane 2). Upon reduction bovine glycoprotein A migrated as a minor band of approximately 28,000 daltons and a major band with an apparent molecular mass of approximately 35,000 daltons. Similar staining characteristics were observed with Coomassie blue and silver staining. This protein is both glycosylated and sialylated (40-42). In some species, other higher molecular weight reduced forms can be observed, presumably due to a second carbohydrate chain (11, $42,43)$. The cDNA for canine (38) and the genomic DNA (44) for human surfactant SAP-35 have been reported. On the basis of these sequences and on enzymatic and chemical studies, it is apparent that SAP-35 contains both globular and collagen-like sequences $(11,38,39,45)$. Present evidence suggests that it interacts with lipid and this interaction is modified by calcium
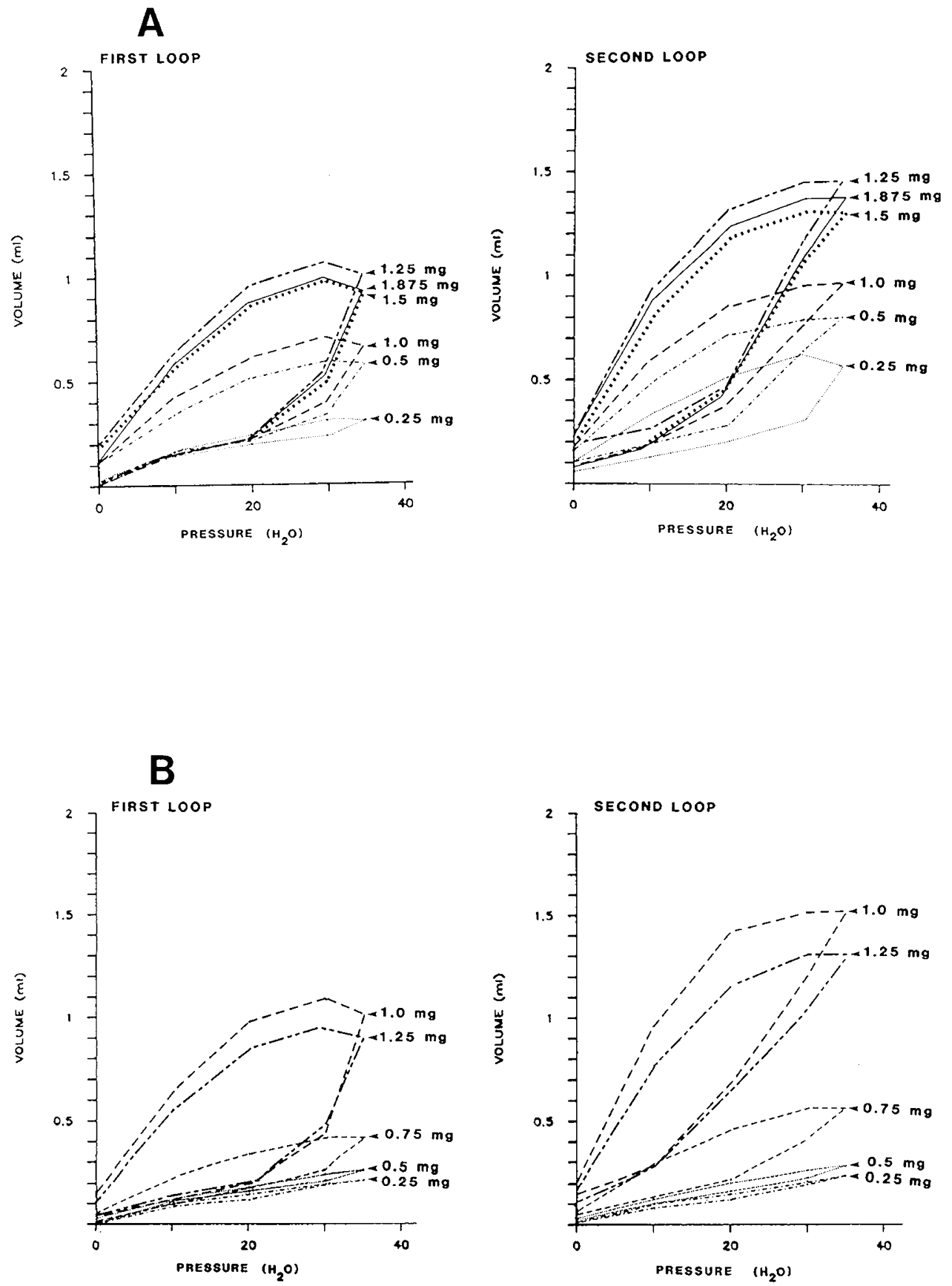

Fig. 2. Pressure-volume curves for fetal rabbit lungs of 27 days gestation with various amounts of lipid extract surfactant $(A)$ and reconstituted surfactant containing $1 \%$ protein relative to lipid $(B)$. The volumes recorded during the first and second loops as indicated in the text are depicted. 
A

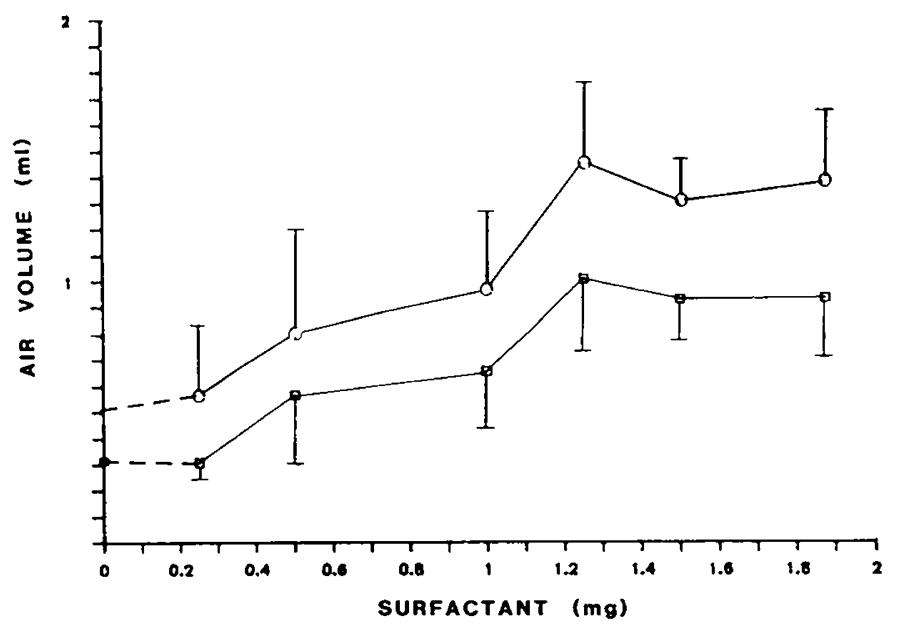

B

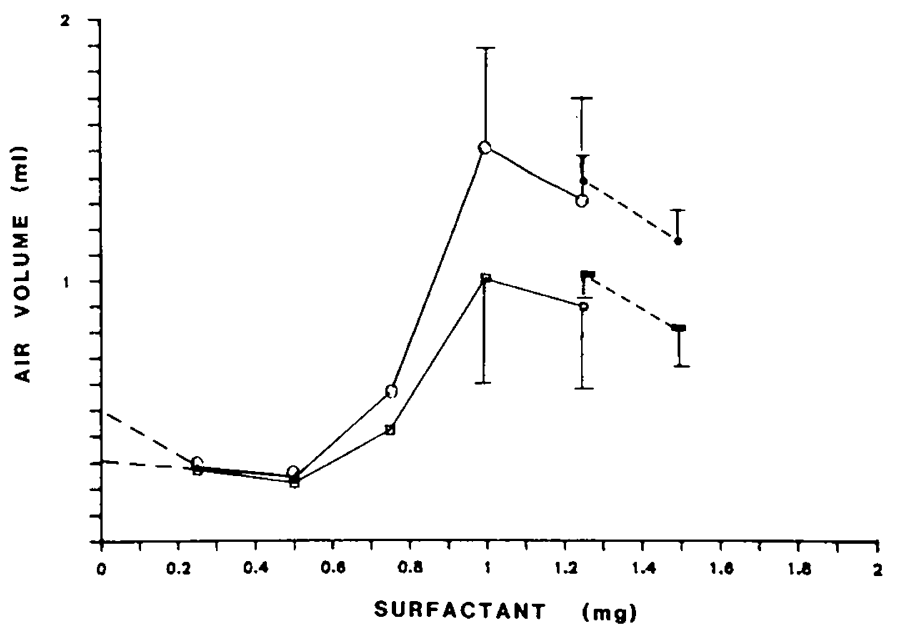

Fig. 3. Comparison of the maximal air volumes achieved during the first and second pressure-volume loops with lungs of prematurely delivered rabbit fetuses. $A$, the effect of increasing amounts of lipid extract on the maximal air volume during the first $(\square)$ and second $(O)$ pressure volume loops. $B$, the effects of various amounts of reconstituted surfactant containing $1 \%$ protein (open symbols) and reconstituted surfactant containing $2 \%$ protein relative to lipid during the first $(\square, \boldsymbol{\square})$ and second $(\mathrm{O}, \bullet)$ pressure-volume loops are plotted.

$(9,10,4,47)$. Circumstantial evidence suggests that SAP-35 is associated with tubular myelin $(48,49)$.

It has been reported that pulmonary surfactant also contains a low molecular mass protein of approximately 14,000 daltons which is a catabolic fragment of SAP-35 (50). This peptide, which has been referred to as glycoprotein $\mathrm{B}$, shares immunological and physical properties with SAP-35 $(2,8,45)$. Glycoprotein $\mathrm{B}$ can be distinguished from the small hydrophobic proteins discussed below on the basis of its glycoprotein nature, its method of preparation, and the lack of immunological cross-reactivity $(23,29,45)$. For reasons that are not clear, this peptide was not detected in bovine pulmonary surfactant (Fig. 1). Little information is available on its biophysical activity.

In addition to SAP-35 and glycoprotein B, pulmonary surfactant contains a number of small molecular mass proteins which can be distinguished from SAP-35 and glycoprotein B by their physical properties, and by the lack of immunological cross- reactivity $(23,30,45)$. The relation between the small molecular mass proteins reported by various workers is complicated by differences in isolation and analytical techniques, but it is clear that they are very tightly associated with lipid and can be extracted with lipid by organic solvents (23-30). SDS-PAGE electrophoresis of bovine lipid extract surfactant revealed hydrophobic proteins with nominal molecular masses of 15,000, 7,000, and 3,500 daltons. Upon reduction, the 15,000-dalton band disappeared and was replaced by a band at 5,000 daltons (Fig. 1). The hydrophobic proteins were more evident after silver staining, particularly in the presence of mercaptoethanol. The possibility that the unreduced 15,000 and reduced 5,000 bands represent the same protein has been corroborated by dansylation studies demonstrating the presence of $\mathrm{N}$-terminal Leu, Phe, and Ile in these two bands (30). Edman degradation and $\mathrm{N}$-terminal analysis of lipid extracts have provided evidence for three hydrophobic peptides which have been designated SAP-6 (Phe), SAP6 (Leu), and SAP-6 (Ile) on the basis of the N-terminal amino acids (30). Limited sequence analysis suggests that SAP-6 (Ile) may be the same as SAP-6 (Leu) with the N-terminal Leu deleted (30). These results are consistent with the view that the 15,000 dalton band is due to an oligomer containing SAP-6 (Phe) and SAP-6 (Leu) or Ile bound by sulfhydryl and other interactions. The 7000- and 3500-dalton bands migrate slightly farther after reduction. Dansylation studies detect only N-terminal Leu and Ile in these bands. It has been suggested that the 7000-dalton band represents dimerization of the 3500-dalton band due to sulfhydryl, hydrophobic, and perhaps other interactions $(26,27$, 29,30 ). However, the possibility of Leu and Ile peptides of variable molecular mass cannot be excluded.

The observations reported herein are in qualitative agreement with other studies on the small hydrophobic proteins associated with pulmonary surfactant from a number of species including dog, cow, pig, and man $(25-29,35,39,51,52)$. Possibly because of the large amounts of SDS used in the sample preparation and in the running buffer (53-55), the apparent molecular masses observed in the present study are slightly lower than those reported by other workers. It is important to note that, in contrast to previous investigation $(23,25-27,29,39,51,52)$, the gel depicted in Figure 1 contains complete lipid extract which has not been subjected to delipidation and/or chromatography. Studies conducted by a number of groups are consistent with the view that pulmonary surfactant contains at least two distinct hydrophobic proteins, SAP-6 (Phe) and SAP-6 (Leu or Ile). SAP6 (Phe), which migrates with a nominal molecular mass of $15-$ 18,000 daltons has been cloned and sequenced from canine and human lung $(39,56)$. SAP-6 (Leu) migrates primarily with a nominal molecular mass of 3500-6000 or as a dimer of this species $(29,30)$. This latter protein contains a polyvaline region containing at least six valines $(29,30,56)$. Further studies are required to evaluate the contribution of these two proteins to surfactant activity.

Perhaps not surprisingly, the amino acid composition of the proteins present in lipid extract surfactant possessed a predominance of nonpolar amino acids when compared to SAP-35 (Table 1). The amino acid analyses presented are similar to those reported for SAP-6 and SAP-35 from cow and from other species $(25,26,29,52)$. The differences in these patterns support the view that it is exceedingly unlikely that the small hydrophobic peptides in lipid extract could represent fragments from the high molecular weight proteins present in pulmonary surfactant.

Recombination of the protein-containing fractions from silicic acid chromatography with pure synthetic DPPC gave rise to a reconstituted surfactant that possessed surfactant properties slightly inferior but statistically indistinguishable from lipid extract surfactant as assessed by the pulsating bubble surfactometer (Table 2). The same results were obtained with the protein content adjusted to either half or to the same relative concentration as that of lipid extract surfactant. The ability of reconstituted surfactants, similar to that reported herein, to mimic the essential 
characteristics of lipid extract surfactant has been reported for the Wilhelmy surface balance $(24,25,39)$ and for a modified Langmuir-Wilhelmy surface tension balance $(24,52)$ as well as with the pulsating bubble surfactometer $(23,30,52)$. The protein fractions used for these reconstitution studies were obtained through chromatography on Sephadex LH-20 (24, 25, 39), silicic acid $(23,30)$, and by detergent extraction $(51,52)$. Examination of the purification schemes and the gel patterns in these publications suggest the presence of variable amounts of the 15,000and 3,500-dalton (unreduced) SAP-6 apoproteins. These preparations did not contain detectable amounts of SAP-35. However, Hawgood et al. (39) suggested that the effectiveness of SAP-6 may be enhanced by the presence of SAP-35. Extensive studies have demonstrated that mixtures of pure lipids rarely duplicate the physicochemical properties of natural pulmonary surfactant or its lipid extract $(4,6)$. Exceptions to this overall rule include mixtures containing hexadecanol as a carrier oil (57) and the hexagonal II phase promoter (58). Whether the biological effectiveness of these preparations will prove adequate for clinical application is still being evaluated.

Considerable evidence has accumulated supporting the biological effectiveness of lipid extract surfactant in compliance and survival studies with prematurely delivered rabbit and lamb fetuses (13-17). Possibly because it is prepared from bovine lung minces rather than bronchoalveolar lavage, the TA-surfactant preparation developed by Fujiwara and coworkers $(18,24,25)$ exhibits superior surfactant properties on a modified LangmuirWilhelmy surface tension balance after being enriched with DPPC, PG, and free fatty acids. Recent studies have indicated that these additions have little effect on the degree to which TA surfactant improved lung expansion and stability in pressurevolume curves, increased tidal volumes during artificial ventilation, or enhanced alveolar volume density in histological sections (57). On the other hand, recent studies by Fujiwara's group indicate that addition of saturated fatty acids increased both the biophysical and the biological effectiveness of a reconstituted surfactant, similar to that reported herein, so that it became indistinguishable from the modified lipid extract preparation (24). The effect of adding free fatty acids to the reconstituted surfactant preparation reported herein must still be examined. Suzuki et al. (52) have demonstrated that reconstituted surfactant 4-5\% low molecular weight proteins from porcine surfactant plus DPPC and dipalmitoyl PG exhibited biophysical activity approaching that of natural surfactant with the pulsating bubble surfactometer and with a modified Langmuir trough-Wilhelmy balance. In addition, these authors observed that administration of their apoprotein-based reconstituted surfactant at $5 \mathrm{mg} / \mathrm{ml}$ produced a 5 -fold increase in tidal volumes of premature rabbit fetuses at an insufflation pressure of $25 \mathrm{~cm} \mathrm{H}_{2} \mathrm{O}$. The effect was similar to that observed with natural surfactant. Possibly because only disaturated lipids were present, the apoprotein-based artificial surfactant was viscous and could not be used at higher concentrations. The reconstituted surfactant described herein, which contains unsaturated PG and PE, possessed similar physical properties to lipid extract surfactant. In contrast to the results observed by Suzuki et al. (52), the latter preparation had little effect at low doses but at the optimal level was indistinguishable from lipid extract surfactant. No difference was observed in the biological effectiveness of reconstitutes containing either half or the same relative protein content as lipid extract surfactant $(2 \%$ $\mathrm{w} / \mathrm{w})$. These investigations, when taken together with the studies of Tanaka et al. (24) and Suzuki et al. $(51,52)$ support the view that an artificial surfactant containing pure lipids plus the SAP6 apoproteins, possibly produced by molecular biology, could be utilized in the prophylactic prevention of the neonatal respiratory distress syndrome.

Acknowledgments. The authors express their gratitude to Mrs. Mary Ann Ormseth for obtaining and purifying the natural bovine and lipid extract surfactant. They also thank Cornell
Abbatoir for their continuing cooperation on the kill floor. Mrs. Barbara McDougall provided editorial expertise.

\section{REFERENCES}

1. Rooney SA 1985 The surfactant system and lung phospholipid biochemistry. Am Rev Respir Dis 131:439-460

2. King RJ 1985 Composition and metabolism of the apolipoproteins of pulmonary surfactant. Ann Rev Physiol 47:775-788

3. Goerke J, Clements JA 1986 Alveolar surface tension and lung surfactant. In: Macklem PT, Mead J (eds) Handbook of Physiology. The Respiratory System. Mechanics of Breathing. American Physiology Society, Bethesda MD, pp 247-261

4. Possmayer F, Yu S-H, Weber JM, Harding PGR 1984. Pulmonary Surfactant. Can J Biochem Cell Biol 62:1121-1131

5. Notter RH, Finkelstein JN 1984 Pulmonary surfactant: an interdisciplinary approach. J Appl Physiol 57:1613-1624

6. Notter RH 1984 Surface chemistry of pulmonary surfactant: the role of individual components. In: Robertson B, van Golde LMG, Batenburg JJ (eds) Pulmonary Surfactant. Elsevier Science Publishers, Amsterdam, pp 1765

7. Bangham AD, Morley CJ, Phillips MC 1979 The physical properties of an effective lung surfactant. Biochim Biophys Acta 573:552-556

8. King RJ 1984 Isolation and Chemical Composition of Pulmonary Surfactant. In: Robertson B, van Golde LMG, Batenburg JJ (eds) Pulmonary Surfactant. Elsevier Science Publishers, Amsterdam, pp 1-15

9. King RJ, MacBeth MC 1979 Physicochemical properties of dipalmitoyl phosphatidylcholine after interaction with apolipoprotein of pulmonary surfactant. Biochim Biophys Acta 557:86-101

10. Hawgood S, Benson BJ, Hamilton RL Jr 1984 Effects of a surfactant-associated protein and calcium ions on the structure and surface activity of lung surfactant lipids. Biochemistry 24:184-190

11. Hawgood S, Efrati H, Schilling J, Benson BJ 1985 Chemical characterization of lung surfactant apoproteins: amino acid composition, $\mathrm{N}$-terminal sequence and enzymatic digestion. Biochem Soc Trans 13:1092-1096

12. Enhorning G 1977 Pulsating bubble technique for evaluating pulmonary surfactant. J Appl Physiol 43:198-203

13. Metcalfe IL, Pototschnick R, Bourgoyne R, Enhorning G 1983 Lung expansion and survival in rabbit neonates treated with surfactant extract. J Appl Physiol 53:838-843

14. Metcalfe IL, Bourgoyne R, Enhorning G 1982 Surfactant supplementation in the preterm rabbit: effects of applied volume on compliance and survival. Pediatr Res 16:834-839

15. Egan EA, Notter RH, Shapiro DL, Kwong MS 1983 Natural and artificial lung surfactant replacement therapy in premature lambs. J Appl Physiol 55:875883

16. Notter RH, Egan EA, Kwong MS, Holm BA, Shapiro DL 1985 Lung surfactant replacement in premature lambs with extracted lipids from bovine lung lavage: effects of dose, dispersion technique and gestation age. Pediatr Res 19:569-577

17. Berggren P, Curstedt $\Upsilon$, Grossman G, Nilsson R, Robertson B 1985 Physiological activity of pulmonary surfactant with low protein content: effect of enrichment with synthetic phospholipids. Exp Lung Res 8:29-51

18. Fujiwara T, Maeta H, Chida S, Morita T, Watabe Y, Abe T 1980 Artificial surfactant therapy in hyaline membrane disease. Lancet 1:55-59

19. Smyth JA, Metcalfe IL, Duffy P, Possmayer F, Bryan MH, Enhorning G 1983 Hyaline membrane disease treated with bovine surfactant. Pediatrics 71:913917

20. Enhorning G, Sheenan A, Possmayer F, Dunn M, Chee CP, Milligan J 1985 Prevention of neonatal respiratory distress syndrome by tracheal instillation of surfactant: a randomized clinical trial. Pediatrics 76:145-153

21. Kwong MS, Egan EA, Notter RH, Shapiro DL 1985 Double-blind clinical tria of calf lung surfactant extract for the prevention of hyaline membrane disease in extremely premature infants. Pediatrics 76:585-592.

22. Shapiro DL, Notter RH, Morin FC, Deluga KS, Golub LM, Sinkin RA, Weiss KI, Cox C 1985 Double blind, randomized trial of calf lung surfactant administered at birth to very premature infants for the prevention of respiratory distress syndrome. Pediatrics 76:593-599

23. Yu S-H, Possmayer F 1986 Reconstitution of surfactant activity using the 6-K apoprotein associated with pulmonary surfactant. Biochem J 236:85-89

24. Tanaka X, Takei T, Aiba T, Masuda K, Kiuchi A, Fujiwara T 1986 Development of synthetic lung surfactants. J Lipid Res 27:475-485

25. Takahashi A, Fujiwara $T 1986$ Proteolipid in bovine lung surfactant: role in surfactant function. Biochem Biophys Res Commun 135:527-532

26. Whitsett JA, Notter RH, Ohning BL, Ross G, Meuth J, Weaver T, Shapiro DL, Holm BA 1986 Hydrophobic 6,000 kilodalton protein and its importance for biophysical activity in lung surfactant extracts. Pediatr Res 20:460467

27. Whitsett JA, Hull WH, Ohning B, Ross G, Weaver TE 1986 Immunologic identification of a pulmonary surfactant-associated protein of molecular weight $=6000$ Daltons. Pediatr Res 20:744-749

28. Taeusch HW, Keough KMW, Williams M, Slavin R, Steele E, Lee AS, Phelps D, Kariel V, Floros J, Avery ME 1986 Characterization of bovine surfactan for infants with respiratory distress syndrome. Pediatrics 77:572-581

29. Phelps DS, Smith LM, Taeusch HW 1987 Characterization and partial amino acid sequence of a low molecular weight surfactant protein. Am Rev Respir Dis $135: 1112-1117$ 
30. Possmayer F, Yu S-H, Chung W, Olafsson R, Harding PGR 1987 Functional studies on the $6 \mathrm{KD}$ apoprotein group associated with pulmonary surfactant. Soc Gynecol Invest 34:60

31. Yu S-H, Harding PGR, Smith N, Possmayer F 1983 Bovine pulmonary surfactant: chemical composition and physical properties. Lipids 18:522529

32. Weber MJ, Possmayer F 1984 Calcium interactions in pulmonary surfactant. Biochim Biophys Acta 796:83-91

33. Bligh EG, Dyer WJ 1959 A rapid method of total lipid extraction and purification. Can J Biochem Physiol 37:911-917

34. Rouser G, Siakotos AN, Fleischer S 1960 Quantitative analysis of phospholipids by thin-layer chromatography and phosphorus analysis. Lipids. 1:8586

35. Phizackerley PJR, Town MH, Newman GE 1979 Hydrophobic proteins of lamellated osmiophilic bodies isolated from pig lung. Biochem J 183:731736

36. Laemmli U 1970 Cleavages of structural proteins during the assembly of the head bacteriophage $T_{4}$. Nature 227:680-685

37. Lowry OH, Rosebrough NJ, Farr AL, Randall RJ 1951 Protein measurement with the Folin phenol reagent. J Biol Chem 193:265-275

38. Benson B, Hawgood S, Schilling J, Clements J, Damm D, Cordell B, Tyler RT 1985 Structure of canine pulmonary surfactant apoprotein: cDNA and complete amino acid sequence. Proc Natl Acad Sci USA 82:6379-6383

39. Hawgood S, Benson BJ, Schilling J, Damm D, Clements JA, White RT 1981 Nucleotide and amino acid sequences of pulmonary surfactant SP18 and evidence for cooperation between SP18 and SP28-36 in surfactant lipid adsorption. Proc Natl Acad Sci USA 84:66-70

40. Ng VL, Herndon VL, Mendelson CR, Snyder JM 1983 Characterization of rabbit surfactant-associated proteins. Biochim Biophys Acta 754:218-226.

41. Weaver TE, Hull WM, Ross GF, Whitsett JR 1985 Intracellular and oligomeric forms of surfactant-associated apolipoprotein(s) A in the rat. Biochim Biophys Acta 827:260-267

42. Whitsett JA, Ross G, Weaver T, Rice W, Dion C, Hull W 1985 Glycosylation and secretion of surfactant-associated glycoprotein A. J Biol Chem 260:15273-15279

43. Phelps DS, Taeusch HW 1985 A comparison of the major human surfactantassociated proteins. Comp Biochem Physiol 82B:441-446

44. White RT, Damm D, Miller J, Spratt K, Schilling D, Hawgood S, Benson B, Cordell B 1985 Isolation and characterization of the human pulmonary surfactant apoprotein gene. Nature 317:361-363

45. Ross GF, Notter RH, Meuth J, Whitsett JA 1986 Phospholipid binding and biophysical activity of pulmonary surfactant-associated protein (SAP)-35 and its non-collagenous COOH-terminal domains. J Biol Chem 261:1428314291

46. King RJ 1984 Lipid apolipoprotein interactions in surfactant studied by reassembly. Exp Lung Res 6:237-253

47. Benson BJ, Williams MC, Sueishi K, Goerke J, Sargeant T 1984 Role of calcium ions in the structure and function of pulmonary surfactant. Biochim Biophys Acta 793:18-27

48. Benson BJ, Hawgood S, Williams MC 1984 Role of apoprotein and calcium ions in surfactant function. Exp Lung Res 6:223-236

49. Wright JR, Benson BJ, Williams MC, Goerke J, Clements JA 1984 Protein composition of rabbit alveolar surfactant subfractions. Biochim Biophys Acta 791:320-332

50. King RJ, Klass DJ, Gikas EG, Clements JA 1973 Isolation of apoproteins from canine surface active material. Am J Physiol 224:788-795

51. Susuki Y, Nakai E, Ohkawa K, Tabata R Effects of apoproteins and phosphotidylglycerol on the surface activity of pulmonary surfactant. Prog Respir Res 18:93-100

52. Suzuki Y, Curstedt T, Grossman G, Kobayashi T, Nilsson R, Nohara K, Robertson B 1986 Experimental studies on the role of the low-molecular weight ( $\leq 15,000$-Daltons) apoproteins of pulmonary surfactant. Eur J Respir Dis 69:336-345

53. Pitt-Rivers R, Impiombato FSA 1968 The binding of sodium dodecyl sulphate to various proteins. Biochem J 109:825-830

54. Swank RT, Munkres KD 1971 Molecular weight analysis of oligopeptides by electrophoresis in polyacrylamide gel with sodium dodecyl sulphate. Analyt Biochem 39:462-477

55. Vacher-Lepretre M, Nicot C, Alfsen A, Jolles J, Jolles P 1976 Study of the apoprotein of Folch-Pi bovine proteolipid. Biochem Biophys Acta 420:323331

56. Glasser SW, Korfhagen TR, Weaver T, Pilot-Matias T, Fox JL, Whitsett JA 1987 CDNA and deduced amino acid sequence of human pulmonary surfactant-associated proteolipid SAPL (Phe). Proc Natl Acad Sci USA 84:40074011

57. Nohara K, Berggren P, Curstedt T, Grossman G, Nilsson R, Robertson B 1986 Correlations between physical and physiological properties of various preparations of lung surfactant. Eur J Respir Dis 69:321-335

58. Durand DJ, Clyman RI, Heymann MA, Clements JA, Mauray F, Kitterman $J$, Ballard P 1985 Effects of a protein-free synthetic surfactant on survival and pulmonary function in preterm lambs. J Pediatr 107:775-780

59. Yu S-H, Harding PGR, Possmayer F 1984 Artificial Pulmonary Surfactant: Potential role for hexagonal HII phase in the formation of a surface-active monolayer. Biochim Biophys Acta 776:37-47 